\title{
Rejoinder from Howell Tong to the discussions on 'Threshold models in time series analysis - 30 years on'
}

\section{Howell TONG}

I am most touched by the kind words from the discussants. As I have no substantial disagreements with their comments, my rejoinder will be brief. It is very gratifying to see that the threshold principle is well accepted (Battaglia, Brockwell, Whittle). Clearly, the introduction of a switching mechanism 30 years ago has proved itself to be a most effective way to implement the principle.

Professor Whittle's reflections are another illustration of the wisdom of Confucius. It is always more instructive to find out how pioneers get to their ideas than what they have developed from them. There should be more books collecting such reflections. Professor Rosenblatt has brought us up to the minute with the latest exciting developments in the realm of mixing and chaos - perhaps two seemingly strange bedfellows to the uninitiated. Of course, we all know that he has distinguished himself by having introduced the celebrated notion of mixing so many years ago. It was already a must when I started my academic career. As for chaos, I can myself still remember the joy shared with Qiwei Yao doing research on the subject in my younger days (- he is still young, of course), and with Kung-Sik Chan when our book on the subject from a distinctly statistical perspective first appeared in 2001. It seems that the book is still unique in adopting this perspective. I admire Weibiao Wu's ingenuity and find his approach to mixing most refreshing. As for its utility in establishing geometric ergodicity in nonlinear autoregression, I see that it can readily furnish general sufficient conditions. At the level of specific models, it would be interesting to find out if it can lead to a condition as sharp as $\alpha<1, \beta<1, \alpha \beta<1$ for Example 4.1. Professor
Hansen's masterly survey is most valuable. It is quite an eyeopener for me, because I must confess that my eyes have, in the past, tended to focus more on ecology/epidemiology than economics/econometrics. He has convinced me that I should be more balanced with my focus in the future. In ecology/epidemiology, I find the development reported in Samia most innovative. I congratulate her and Kung-Sik Chan for having developed a very powerful tool to nonlinear time series modelling of non-normal (especially count) data. I think that such a tool has been long overdue.

This is a fitting moment for me to thank belatedly the 1980 Research Section, of the Royal Statistical Society, chaired by Professor Whittle, for accepting the threshold paper for discussion. It was a bold decision on their part because all that the paper did was to describe some new ideas without much technical detail. The paper was definitely nonrigorous as there was hardly any serious theorem. I am sure that the paper would have almost zero probability of being accepted by a different committee.

Last but not least, I would like to record my warmest thanks to Qiwei Yao, Kung-Sik Chan and Wai-Keung Li for organizing the special event and to Statistics and Its Interface for giving me the opportunity to reflect fondly on the past and look forward confidently to the future.

\author{
Howell Tong \\ London School of Economics and Political Science \\ London, UK \\ E-mail address: howell.tong@gmail.com
}

